\title{
CORPO SEM VONTADE IMERSO EM COISAS VIVAS
}

\author{
Helena Bastos ${ }^{1}$
}

\section{RESUMO}

Que lugar é dado a vida? Talvez, uma ideia de escuta possa nos afinar sobre que corpo vem se projetando e se intensificando ao nosso alcance. Este texto propõe uma exploração espaço-temporal de percepções que nos invadem enquanto trajetórias espiraladas.

PALAVRAS-CHAVE: corpos apps, escuta, hospitabilidade, pandemia

\section{CUERPO SIN VOLUNTAD INMERSO EN COSAS VIVAS}

\author{
RESUMEN \\ ¿Qué lugar se le da a la vida? Quizás, una idea de escuchar puede \\ refinarnos sobre qué cuerpo ha estado proyectando e intensificándose a \\ nuestro alcance. Este texto propone una exploración espacio-temporal de \\ percepciones que nos invaden como trayectorias espirales.
}

PALABRAS CLAVE: cuerpos de apps, escucha, hospitalidad, pandemia

\section{BODY WITHOUT WILL IMMERSED IN LIVING THINGS}

\begin{abstract}
What place is given to life? Perhaps, through the aesthetic experience generated by listening, we can understand the relationship between body and environment. This article proposes a space-time exploration of perceptions as spiral trajectories.
\end{abstract}

KEYWORDS: apps bodies, listening, hospitality, pandemic

$$
* * *
$$

\footnotetext{
1 Bailarina, coreógrafa e professora na graduação e pós-graduação do Departamento de Artes Cênicas/CAC da Escola de Comunicações e Artes da USP. Integra junto ao Programa de Pós-Graduação em Artes Cênicas/PPGAC da ECA/USP, as linhas de pesquisas Texto $e$ Cena e Formação do Artista Teatral. Título de Doutora em Comunicação e Semiótica pela PUC/SP. Trabalha sistematicamente com o Grupo Musicanoar (1992) como diretora e artista da dança.
} 
Estamos em tempos cujas discussões sobre o corpo estão bastante expostas e são ao mesmo tempo banais. Expostas enquanto assunto onipresente em todas as áreas do conhecimento, sejam essas por onde transitamos. Banais, pois tanta exposição parece nos paralisar diante de ênfases plurais, porém captadas sob naturalizações como se não percebêssemos transformações que vem nos envolvendo e nos entorpecendo já faz um certo tempo. Uma referência é a Pandemia Covid-19 que se irriga por todo o mundo. Mantemo-nos em quarentena na tentativa de nos proteger, apesar de percebermos que neste embate a luta já parte de modo desigual da perspectiva social, pelo menos no Brasil. Muitas vidas ceifadas, além das populações mais carentes ficarem às derivas, lançadas à própria sorte. Os grandes fluxos urbanos se transformam em corredores mais esvaziados. No contexto paulistano, ao caminharmos pelas ruas em alguns momentos, por necessidades de reabastecermos nossa comida, percebemos uma desaceleração n(d)esse urbano. Na capital de São Paulo, desde 17 de março de 2020, pelo menos. Intuímos que algo similar aconteça em outros estados, em outras cidades do Brasil. Enfim, muitos corredores de asfalto pelo mundo, nos reapresentam neste período pandêmico, cidades esvaziadas de gente e carro também.

\section{Silêncios?}

Talvez em determinadas camadas um nível de silêncio pode ter nos invadido, mas em outras, a aceleração continuou, se deslocou para outros ambientes com muitas simultaneidades e constâncias. Um outro mundo, que já nos coabitava, mas não o percebíamos com tantas ênfases e ordenações: paralelo a estes "esvaziamentos de corredores urbanos", as telas de nossos computadores nos expõem cotidianamente o quanto estamos plugados. Nos alerta que o mundo, apesar da Pandemia, não parou. O mercado está nervoso. A universidade também nervosa, não parou. As lives nos inundam em nossas casas. Geram-se certos pânicos na relação com o poder, entre poderes e nas suas capacidades de ditarem quem pode viver e quem deve morrer. Na interrogação do filósofo camoronês Achille Mbembe: "que lugar é dado à vida, à morte e ao corpo humano (em especial o corpo ferido ou 
massacrado)? Como eles estão inscritos na ordem do poder?" (MBEMBE, 2018, p.7).

Mbembe nos provoca na sua noção de "Necropolítica" como formas contemporâneas em que o político é considerado uma forma de guerra. Nessa direção, sua preocupação é "com aquelas formas de soberania cujo projeto central não é a luta pela autonomia, mas 'a instrumentalização generalizada da existência humana e a destruição material de corpos humanos e populações"' (MBEMBE, 2018, p.10 e 11).

\section{Quanto vale a vida?}

O tempo Covid-19 opera com base na divisão entre quem pode viver, quem pode morrer. Pobres ou ricos; jovens ou idosos; negros/indígenas/pardos/brancos; heteros/homo/bis/trans; pessoas com necessidades especiais ou não; nesse tecido de distintas gentes, uma imensa maioria são lançad@s ao poderio do capital enquanto possibilidades criadoras ou devoradoras, ou outras, descartadas conforme suas condições. No Brasil, a maioria da população é deixada a sua própria sorte, pois sabemos que quanto mais vulnerável socialmente, a possibilidade de contaminação aumenta diante desta pandemia.

Que lugar é dado a vida? Diariamente vemos na televisão as entrevistas de governantes nos apresentando estatísticas e projeções diante das vidas que partem por um vírus que silenciosamente, ao encontrar um ambiente adequado, pode invadir qualquer um/uma de nós. Mas novamente, vemos, que os mais pobres são os mais atingidos. É trágico porque apesar de muita luta, um final eterno parece abraçar silenciosamente muitos entre nós. Quantos nós. Quem diria, um ser invisível aos nossos olhos, sem barulho, vai penetrando por nossas vias respiratórias, até nossa dificuldade ser tanta, que tocamos um último suspiro e nos despedimos dessa vida. Que lugar é dado a vida? Esta interrogação vai nos confrontando com um tipo de poder que vai se definindo em relação também a um campo biológico - do qual toma controle. "Esse controle pressupõe a distribuição da espécie humana em grupos, a subdivisão da população em subgrupos e o estabelecimento de uma cesura biológica entre uns e outros" (MBEMBE, 
2018, p.17). O assunto corpo está sempre sujeitado e ainda assim, somos interpelados por necessidades de adequações às urgências deste tempo, que não pode parar no enfrentamento de novos mundos: ora projetados, ora cuidados, ora despejados, ora deletados. Nesse horizonte somos levados a enfrentar em escala mundial possibilidades entre permanências, invisibilidades e esquecimentos.

Uma lógica: Corpos Apps. Talvez, uma ideia de escuta possa nos afinar e nos interrogar sobre que corpo vem se projetando e se intensificando ao nosso alcance. A pesquisadora Helena Katz fala da lógica do software. Ela nos alerta sobre "corpo apps/vida apps. Apps = aplications programs" (KATZ, 2015, p. 240). Sublinha que estamos lidando com a vida e com o corpo como se eles fossem "programas aplicados" e estivessem sendo sempre reestruturados, reprometidos, redesenhados. "As explicações de 'como' reprogramar variam, por isso vivemos no estado de sempre alerta para não perder qualquer mudança na instrução” (KATZ, 2015, p. 240).

Sublinha-se uma transformação contundente: "da preocupação em identificar os dispositivos e a sua ação em nossas vidas passaram a ser pautadas pela lógica do aplicativo" (KATZ, 2015, p.240).

O mundo mudou, e aquele mundo (de antes da Covid-19) não existe mais. Como reconhecermos corpo, diante desse cenário do mundo dos dispositivos para o viver pensado e praticado como aplicativo? Não é possível ignorar nossas mudanças, em termos de hábitos diante do contexto pandêmico. Não falamos aqui simplesmente da alteração de nossas rotinas nesses dias de isolamento. Mas podemos refletir nas mudanças mais profundas, naquelas transformações que devem moldar a realidade à nossa volta e, claro, as nossas vidas. Nessa conjuntura somos levadas/os a enfrentar sensações trágicas como o fim do mundo ou o medo de morrer. $\mathrm{Na}$ linha do horizonte, a passagem do século XX para o XXI ganha um acento concreto com a contaminação da Covid-19.

Outro mundo. Não pretendemos seguir um fluxo cristão carregado de culpas sobre nossas escolhas e as consequências em nosso planeta. Ao mesmo tempo, precisamos reconhecer, que, como humanos temos feito 
péssimas escolhas nesse mundo. Tais escolhas vem afetando consideravelmente a vida dos animais, das florestas, dos rios, das plantas, dos mares, por exemplo. Por mais trágico que a Covid-19 seja, está nos mostrando também a capacidade de recuperação da natureza. Uma referência é a diminuição da poluição na região metropolitana de São Paulo nesta pandemia, sob o efeito da nossa quarentena comparada com ano passado. Outras referências de nossos atuais habitats podem ser pontuadas como céus mais limpos, cidades mais silenciosas, pessoas asmáticas com menos crises, entre alguns exemplos.

Em dança sabemos de um reino Sol. Luís XIV² escolheu para emblema o Sol e, assim, apelidado de "o Grande" e "Rei Sol". Ele reinou como tal sobre a corte, sobre os cortesãos e sobre a França e Navarra.

Luís XIV vivia conforme suas tradições no século XVII em que reis e rainhas detêm o exercício de poderes monárquicos sobre um território designado de reino, sob uma política governamental conhecida por monarquia. Politicamente o século XVII na Europa é caracterizado pela monarquia absolutista que nasce com este rei conhecido como "ReiSol". Durante os séculos XVI e XVII, diversos pensadores procuraram justificar o poder absoluto dos monarcas. A principal obra de Nicolau Maquiavel ${ }^{3}$, O príncipe (1513), foi escrita para responder a um conjunto de questões a respeito da origem e da manutenção do poder, influenciou os monarcas europeus, que a utilizaram para a defesa do

\footnotetext{
2 Luís XIV, apelidado de "o Grande" e "Rei Sol" (1638-1715). A Academia Real de Dança foi uma instituição educativa fundada em Paris, pelo rei Luís XIV, em 1661, tendo como seu primeiro diretor François Galant du Désert. O objetivo foi normatizar o ensino e a prática da dança nacional. A academia foi fundada após uma petição de alguns mestres de dança, e, no ato, o rei elegeu treze dos mestres mais antigos como acadêmicos. Suas funções deveriam ser elevar a qualidade da arte e organizar o ensino, considerando a dança como uma forma de conhecimento. Luís XIV tinha elevado apreço pela dança e se apresentou pessoalmente em várias oportunidades, não só em bailes palacianos, mas também como bailarino protagonista em encenações suntuosas diante de toda a corte, incorporando a figura mítica do Rei-Sol. https://pt.wikipedia.org/wiki/Lu\%C3\%ADs_XIV_de_Fran\%C3\%A7a (Acesso em 11/06/2020).

${ }^{3}$ Nicolau Maquiavel (1469 -1527) Florença, Itália. Filósofo. Reconhecido como fundador do pensamento e da ciência política moderna.
} 
Absolutismo ${ }^{4}$. Maquiavel propunha o Estado como um fim em si mesmo, alegando que os soberanos poderiam empregar-se de todos os meios analisados lícitos ou não - que afiançassem o triunfo e continuidade do seu poder.

Uma flecha atravessando tempos. Nesse corte súbito, propomos um exercício espaço-temporal. Nesse e desse mover, pensemos sobre um reino organizado, politizado do século XVII. Tudo gira em torno do rei. Não à toa, quando Luís XIV cria a Academia Real de Dança, vai projetar nela seu estilo de governança. Ao eleger o Sol como emblema, Luís XIV nos comunica que reina como o astro que dá vida a qualquer coisa, é também o símbolo da ordem e da regularidade. A pesquisadora Ana Cristina Echevenguá Teixeira nos demonstra "que a relação de arte e poder se afirma enfaticamente na corte, em que a aparência, a imagem e o lugar ocupado nas danças determinavam a imagem pública de alguém" (TEIXEIRA, 2012, P. 40). Recordemos que na corte, o rei se mostra em espetáculo. Nesse ambiente, rito de festa real, o espaço é vivenciado hierarquicamente em reverência ao rei Sol, e seu reino gira em torno de como ele, rei, capta o mundo. Se ampliarmos o campo que essa flecha temporal atinge, vamos identificar reverberações de um pensamento antropocêntrico ${ }^{5}$.

Ao trazermos estas possibilidades de cruzamentos entre temposespaços é para pensarmos em determinadas coincidências que atravessamos, por exemplo, com o atual governo federal. Parece que o atual Chefe de Estado do Brasil (2019-2020) ainda se mostra apegado a uma compreensão

4 O Absolutismo foi um sistema político que, em geral, defendia o poder absoluto do monarca sobre o Estado e foi muito comum essa forma de governo estava diretamente ligada com o processo de formação dos Estados Nacionais (nações modernas) e com a ascensão da classe mercantil conhecida como burguesia, assim como se relacionava a uma série de outras transformações ocorridas na Europa desde a Baixa Idade Média. https://www.historiadomundo.com.br/idade-moderna/o-absolutismo-e-o-rei.htm (Acesso em 13/06/2020).

${ }^{5} \mathrm{O}$ antropocentrismo (do grego anthropos, "humano"; e, kentron, "centro") é uma concepção que considera que a humanidade deve permanecer no centro do entendimento dos humanos, isto é, o universo deve ser avaliado de acordo com a sua relação com o ser humano, sendo que as demais espécies, bem como tudo mais, existem para servi-los. O antropocentrismo coloca o ser humano no centro do universo, postulando que tudo o que existe foi concebido e desenvolvido para a satisfação humana.

https://pt.wikipedia.org/wiki/Antropocentrismo (Acesso em 12/06/2020). 
absolutista de governança. Eis um perigo que nos rodeia: ditadura em pleno século XXI.

Uma flechada explode em céus. "Somos todos poeiras das estrelas" esta frase, tornada famosa pelo astrônomo Carl Sagan, significa basicamente que todos os elementos que formam os seres humanos, os vegetais, as rochas e tudo o mais que existe no planeta foram formados há bilhões de anos, durante a explosão de estrelas a anos luz de distância daqui. É isso mesmo: elementos pesados como o ferro que corre no nosso sangue, ou o ouro que compõe as nossas joias, só podem ser sintetizados na natureza em condições extremas de temperatura e pressão - ou seja, quando uma estrela morre e explode violentamente, virando uma supernova. O material formado, então, se espalha pelo espaço interestelar, podendo dar origem a novas estrelas e planetas. Precisamos mudar a chave de que a figura humana é o centro de tudo, apesar de sabermos que há muitos que se voltam para uma compreensão de convivências mais horizontais com tudo o que nos cerca. Como nos alerta o cacique do povo Krenak e ativista Ailton Krenak:

É terrível o que está acontecendo, mas a sociedade precisa entender que não somos o Sal da Terra. Temos que abandonar o antropocentrismo; há muita vida além da gente, não fazemos falta na biodiversidade. Pelo contrário. Desde pequenos, aprendemos que há listas de espécies em extinção. Enquanto essas listas aumentam, os humanos proliferam, destruindo florestas, rios e animais. Somos piores que a Covid-19. Esse pacote chamado de humanidade vai sendo descolado de maneira absoluta desse organismo que é a Terra, viver numa abstração civilizatória que suprime a diversidade, nega a pluralidade das formas de vida, de existência e de hábitos. (KRENAK, 2020)

Desse nosso atual contexto pandêmico, uma pergunta: vivemos um fim de mundo? De fato, nosso planeta um dia findará. Mas, a princípio ele ainda tem condições reais de temporalidades e permanências bem extensas. Porém, torna-se urgente responsabilizar-nos pelo modo como estabelecemos nossa convivência nesse mundo, de modo mais horizontal. Caso contrário, distintas catástrofes nos engolirão. Quem sabe as dores de perdas de vidas tão próximas a muitos de nós, leve-nos a questionar sobre nossa humanidade. Este vírus elegeu a humanidade. Se prestarmos atenção ao nosso redor perceberemos que as plantas continuam crescendo e outros animais, os não humanos estão vivendo. 
Moveres entre esquecimentos? Vale repensarmos sobre as condições que estamos elegendo nossos viveres. Lilia Schwarcz, professora da USP, lança que "No futuro, professores precisarão investir algumas aulas para explicar o que vivemos hoje"6. Recordemos que o longo século XIX terminou com a Primeira Guerra Mundial, com mortes, com a experiência do luto, e também o que isso significou sobre a nossa capacidade destrutiva. Uma hipótese é que essa nossa pandemia marca o final do século XX, considerado entre muitos, o século da tecnologia. Nós tivemos um grande desenvolvimento tecnológico, mas agora a pandemia mostra esses limites. Em entrevista para a BBC o doutor em microbiologia Átila Iamarino nos expõe: "Mudanças que o mundo levaria décadas para passar, que a gente levaria muito tempo para implementar voluntariamente, a gente está tendo que implementar no susto, em questão de meses"7, diz ele. A experiência humana é responsável pelo tempo que se habita. A partir das questões levantadas propõe-se uma reflexão que enuncia um modo do corpo existir. Como abarcar nessa crise possibilidades de outras compreensões sobre o que este mundo nos obriga a enfrentar enquanto extensões de nossos corpos?

“Isto é um ensaio geral?" Bruno Latour nos alerta: “a súbita e dolorosa percepção de que a definição clássica de sociedade - humanos entre si - não faz sentido. O estado da sociedade depende de cada momento das associações entre muitos autores, a maioria dos quais não possui formas humanas." (LATOUR, 2020). Entre realidades presenciais e virtuais somos lançados em ondas em que tudo é pontuado com um determinado prazo, pois tempo é dinheiro. Alguns autores especializados em finanças pessoais afirmam que, atualmente a riqueza é expressa em tempo e não mais monetariamente. O que isso quer dizer? Se você parar de trabalhar hoje, por quanto tempo você mantém o seu padrão de vida? Se tivermos oportunidade de nos observar com um certo distanciamento sobre nossas tarefas, teremos a certeza de moveres produtivistas que nos interpelam a agir na ênfase de

\footnotetext{
${ }^{6}$ https://www.hypeness.com.br/2020/04/lilia-schwarcz-sobre-coronavirus-pandemia-marcao-final-do-seculo-20/ (Acesso em 12/06/2020).

${ }^{7}$ https://brasil.elpais.com/opiniao/2020-04-13/como-o-coronavirus-vai-mudar-nossas-vidasdez-tendencias-para-o-mundo-pos-pandemia.html (Acesso em 13/06/2020).
} 
muitas coisas inúteis. Apesar do estardalhaço em torno de uma batalha contra o vírus da Covid-19, isso é apenas um elo:

de uma cadeia em que o gerenciamento de estoques e máscaras ou testes, a regulamentação de direitos de propriedade, hábitos cívicos, gestos de solidariedade, importam exatamente na definição do grau de virulência do agente infeccioso. Uma vez que toda a rede da qual ele é apenas um elo é levada em consideração, o mesmo vírus não age de uma mesma maneira em Taiwan, Cingapura, Nova York ou Paris... (LATOUR, 2020) ${ }^{8}$

Em situações de catástrofes, como a Pandemia da Covid-19, revelam uma lógica de funcionamento e de atuação do capitalismo, e como, no limite, o Estado deveria garantir apoio e planos de reconstituição dos laços sociais e das comunidades, após a ocorrência de um desastre. Argumenta-se que o Estado é o mediador e o recurso de última instância legitimador da integração das sociedades no capitalismo global, e que a linha abissal que define os integrados, os descartáveis, os invisíveis nos envolve ou nos engole. Discute-se criticamente a noção de risco, e como as catástrofes podem ser reveladoras da lógica do capitalismo e dos limites do neoliberalismo. Em tempo de pandemia pela Covid-19, precisamos focar no papel das vítimas, dos afetados e na forma como eles nos exigem outra possibilidade de analisar o sofrimento, para além das abordagens convencionais do trauma. Talvez pensarmos na construção de uma política radical de alteridade.

De Luís XIV, do Absolutismo (sec. XVI até do sec. XIX em partes da Europa) à Pandemia da Covid-19 (século XXI) vão se expondo modos de existências a partir de diversas experiências humanas agindo no tempo.

Uma escuta redimensionando nossos moveres. A partir das ponderações expostas até aqui, retomamos a ideia de escuta. Compreender como ela pode colaborar na mediação desses tempos que nos parecem devolver sentidos de "sem tempos". Antes, nos detemos sobre o que estamos apresentando como escuta: reconhecemos como um estado de prontidão que pode colaborar a pensarmos e resolvermos problemas ligados a um determinado assunto. Como assunto, entendemos uma diversidade de temas que podem estar ligados a uma indagação filosófica, a uma frase poética, a uma sonoridade ou um simples deslocamento ou queda do corpo. O

\footnotetext{
${ }^{8}$ https://n-1edicoes.org/textos-1 (Acesso em 13/06/2020).
} 
pensamento de outro termo surge com a escuta, prontidão. Pontuamos aqui também uma possibilidade estética, o que toma por base a relação do conhecimento em uma mesma escala temporal. Agindo conhecendo, conhecendo agindo. Simultaneamente, na medida em que vivemos, compreendemos como este estado de prontidão pode nos atravessar em outras instâncias do nosso viver ao nos propormos uma determinada escuta. Desta forma, examinando a experiência como um método de atenção/consciência, percebemos que existem muitas atividades $d(n) o$ corpo que pressupõem este tipo de relação.

A concentração exigida na prática criativa - escuta - gera estados de atenção que pretendem trazer a pessoa para mais perto de sua experiência. Neste sentido, apontamos a importância desta ação na relação com o autoconhecimento. Gerar este estado de prontidão a partir da escuta é disponibilizar o corpo para que ele não se isole.

O pensamento é que este estado gerado pela escuta consiga organizar-se em direção a alguma coisa, interagindo com um fluxo dos acontecimentos ao redor de si, que se envolve com o meio ambiente e com os estímulos vindos não só do corpo, mas, das relações estabelecidas com o ambiente. Nossa ideia é captar uma compreensão que disponibilizamos no corpo - processo de inúmeros acordos - entre diferentes informações com o ambiente, transferindo esse seu jeito de acontecer para outras instâncias de seu funcionamento. Ou seja, a ação criativa de um corpo no mundo recria os modos que o produziram como uma onda que chega e parte, qualificada por favorecer e quebrar contatos. Podemos captar a escuta enquanto possibilidades estéticas na ação criativa do corpo. Acoplado ainda a esse entendimento de escuta evocamos o termo hospitabilidade que é experienciado há muito tempo.

Conforme o professor Conrad Lashley expõe, hospitalidade "tem a ver com trazer convidados para o nosso mundo, respeitando suas próprias condições" (LASHLEY, 2015, p.75). Rememoremos que a fé muçulmana surgiu em algum momento no século VII d. C. e o ensino cristão dois mil anos atrás, a escrita dos judeus aparece em torno de setecentos anos antes 
disso. Nestas três referências, as religiões são monoteístas e cada uma a seu modo defende o comportamento hospitaleiro que apoia seus legados religiosos cujas origens são anteriores como dos ensinamentos hindus, surgido há mais de cinco mil anos. Oferecer hospitalidade ao estrangeiro é característica fundamental das crenças e da cultura hindu. Em particular o hóspede inesperado deveria ser especialmente honrado e chamado de atithi, termo que traduzido literalmente significa "sem um tempo estabelecido" $(\mathrm{KHAN}, 2009)^{9}$. Prega um ditado popular que "o hóspede inesperado deve ser tratado tão bem quanto um deus” (MELWANI, 2009) 10. Lashley nos informa: "A tradição ensina que mesmo os mais pobres devem oferecer ao menos três coisas: palavras doces, um lugar para sentar e refrescos (no mínimo, água)" (LASHLEY, 2015, p.77). Há outro ensinamento que diz "Mesmo a um inimigo deve ser oferecida hospitalidade apropriada se ele vier à sua casa. Uma árvore não nega sua sombra mesmo àquele que veio cortála” (LASHLEY, 2015, apud Mahabharata 12.372) ${ }^{11}$.

Ao que parece o conceito "hospitabilidade" nos foi introduzido inicialmente pelos muçulmanos. Esta ideia nos foi apresentada por Christian Dunker, professor da USP, na sua palestra intitulada "Educação e Escuta” no I Congresso de Graduação da ECA/USP (2019). De acordo com Dunker, quando se faziam as viagens e expedições pelos desertos, os mulçumanos inventaram o "decreto da hospitabilidade". O ritual sinalizava: primeiramente oferecemos pão e água. A seguir, esperamos que a primeira palavra seja do outro. Para escutar tem que exercitar ser o anfitrião.

Quanto ao anfitrião há duas histórias: 1. O mito de Anfitrião e Alcmena em Ovídio.12 2. Outro é que o tema da "Hospitalidade Islâmica"

\footnotetext{
${ }^{9}$ KHAN, N. Definitions of hospitality in religions \& regions, internet, 2009.

10 MELWANI, L. Hindu hospitality: the Gods amongst us, Hinduism Today, 2009.

11 MAHABHARATA, 12.372.

12 Alcmena é uma personagem da Mitologia Grega, mulher de Anfitrião e mãe de Héracles (ou Hércules). Enquanto o seu marido estava na guerra, Zeus tomou a sua forma para enganar Alcmena, tendo com ela seu filho Hércules. https://pt.wikipedia.org/wiki/Alcmena (Acesso em 14/06/2020).
} 
está no Corão. Explicação do Hadith ${ }^{13}$ :

Aboo Hurayrah relatou que o Mensageiro de Allah (سدلم و عل يه اله ىصل) disse: "Quem crê em Allah e no Último Dia deve dizer coisas boas ou calar-se, ser gentil com seus vizinhos e hospitaleiro para com os seus convidados." (Coletado por alBukhari e Muslim)

A qualidade da hospitalidade tem sido um dos mais poderosos meios de propagação do Islam ${ }^{14}$. Quando os comerciantes muçulmanos se estabeleceram no Sudeste da Ásia e da África, esta qualidade de hospitalidade espantou as populações entre as quais viviam. O Profeta Muhammad (سدلم و علديه الله صدلى) deu ênfase a estas três características devido ao valor que elas têm (lugar para descansar, pão e água, escutar). Os muçulmanos acreditam em Allah e no Último Dia, mas se a crença não é praticada, como por exemplo, evitando calúnia e sendo bondoso para com os vizinhos e convidados, então não será nada mais do que palavras vazias. É interessante porque podemos fazer uma relação de como as palavras que enunciamos tem suas responsabilidades, seu peso dependendo do contexto. "Do fruto da boca enche-se o estômago do homem; o produto dos lábios o satisfaz. A língua tem poder sobre a vida e sobre a morte; os que gostam de usá-la comerão seu fruto" (PROVÉRBIOS, 18:20-21).

Nos tempos atuais, temos muita dificuldade de gerarmos silêncios. Para conectarmos ao nível de escuta que apresentamos até aqui, precisamos exercer silêncios. Na Bíblia, está escrito, "Mas Jesus retirava-se para lugares solitários e orava.” (LUCAS, 5:16). Quando silenciamos podemos ouvir melhor, podemos sentir melhor. Quando silenciamos nos disponibilizamos para outros sons e outras formas. O silêncio pontua que esta escuta não é passiva. É um estado corporal que nos disponibilizamos

13 Hádice[1] ou Hadiz (em árabe: ال حدي ث; transl.: Hadith, pl. Ahadith) é um corpo de leis, lendas e histórias sobre a vida de Maomé, (estas histórias chamam-se em Árabe Suna e incluem a sua biografia, ou sira) e os próprios dizeres nos quais ele justificou as suas escolhas ou ofereceu conselhos; muitas partes do hádice lidam com os seus companheiros (Sahaba). https://pt.wikipedia.org/wiki/H\%C3\%A1dice (Acesso em 14/06/2020)

14 Islão (pt) ou islã (pt-BR) (em árabe: ملام !; transl.: Islām) ou islamismo [nota 1] é uma religião abraâmica monoteísta articulada pelo Alcorão, um texto considerado pelos seus seguidores como a palavra literal de Deus (Alá, em árabe: لهال ; transl.: Allāh), e pelos ensinamentos e exemplos normativos (a chamada suna, parte do hádice) de Maomé, considerado pelos fiéis como o último profeta de Deus. Um adepto do islão é chamado muçulmano. https://pt.wikipedia.org/wiki/Isl\%C3\%A3o (Acesso em 13/06/2020). 
em direção ao próximo. Nesse contato, o silêncio é muito importante para que possamos compreender em parte, como as palavras nos invadem e nos provocam. Assim, podemos ponderar sobre alguns ensinamentos:

1. Este hadith mostra a preocupação Islam para a expressão prática de seus princípios de fé.

2. É preferível ficar em silêncio se não há nada bom que se possa dizer.

3. Os vizinhos devem ser tratados com a mesma bondade mostrada ao parente mais próximo.

4. O muçulmano deve ser sempre hospitaleiro com seus hóspedes. (Sheikh Abu Ameenah Bilal Phililps)

Revendo a palestra de Dunker, ele nos apresenta quatro níveis de escuta: 1) Hospitabilidade; 2) Segundo nível: Hospital. Para onde vão as conversas? Como atravessamos sobre os problemas? 3) Etiologia. A etiologia é o estudo ou ciência das causas. Não há que se falar em "etiologia" como termo restritivo de uma ciência isoladamente. Nesse contexto, tem a ver, por exemplo, com o modo como narramos uma situação ou sofrimento. 4) Hospedeiro: a- Quando conta uma história expõe uma narrativa; bAprender a contar história; c- Representar o conflito; d- Afetar por aquilo que o outro não sabe de si.

Ao trazermos a ideia de escuta acoplada com a ideia de hospitabilidade, queremos pontuar a escuta enquanto uma experiência estética. Compreendermos que neste estado de escuta, a partir da narrativa do outro, eu mobilizo o meu corpo (cognitivamente) para uma experiência provocada pela maneira como o outro me narra um episódio.

Escutar é produzir experiência estética a partir da visão do outro. Se concordamos ou não com o discurso, não é uma questão aqui. Antes de tudo, precisamos nos propor a uma escuta. Escutar tem a ver com empatia. Escutar não é identificar, mas exercer um sentimento estético da forma, um sentimento que nos produza uma viagem, uma travessia. É produzir algum tipo de deslocamento. "Afetar-se por aquilo que o outro não sabe de si".

Trajetórias Espiraladas de Coisas Vivas. Este texto foi sendo construído enquanto uma exploração espaço-temporal. Percepções que nos invadem enquanto trajetórias espiraladas envolvendo diferentes naturezas de corpos por onde circulamos, rastreamos, tateamos. Nos percursos de 
nossa história, nossa humanidade ${ }^{15}$ expõe caminhadas constantes. Trajetórias despontam em horizontes cujos percursos invadem e envolvem outros tempos, outras gentes. Nessa especulação espaço-temporal sobrevivemos aos desertos, enfrentamos savanas, deparamos com tempestades, sempre na vontade de expandir. Agora, a natureza nos impõe outro limite, para permanecer, tem que parar e respirar. Precisamos aprender de novo, não é paralisar. No futuro precisaremos contar aos próximos o que é isto que estamos vivendo ou como sobrevivemos.

Uma realidade é que somos todos provisórios, mas como semearmos futuros para as gerações seguintes? O movimento em espiral está no mundo: desde os movimentos de alguns corpos celestes, na fumaça que surge de uma xícara quente de café, na formação muscular dos corpos humanos, na dupla hélice do DNA, nas impressões digitais e, porque não lembrar, do deslocamento em espiral, nas estratégias de locomoção espacial como formas de sobrevivência.

Desses tateamentos espiralados, formalizo-os enquanto estratégias de continuar vivendo, e, desse modo, demonstro como o pensamento espiral habita o universo que compomos. Nesta reflexão, associo processamentos de tempos-espaços contaminados por ideias compreendidas no acoplamento entre experiência, escuta e hospitabilidade. Tudo se envolvendo por trajetórias espiraladas

Escutar não é identificar, porém exercer uma emoção que nos provoque outras travessias. Estas nos lançam em ambientes conhecidos ou não. Tais deslocamentos, capturo-os enquanto moveres estéticos. Afetam-nos sempre, mesmo quando temos dificuldades de percebê-los. Captamos também modificações nos nossos hábitos cotidianos cujos ambientes de telas estão se impondo cada vez mais sobre nossas ações, dia após dia. Precisamos enfrentar e mergulhar no modo como cognitivamente, estamos nos transformando e adaptando. Já havia um certo tempo que o mundo emanava sinais de suas severas transformações.

15 O Homo sapiens surgiu na África Oriental por volta de $300 \mathrm{mil}$ anos atrás https://pt.wikipedia.org/wiki/Humano (Acesso em 16/06/2020) 
A Covid-19 nos sinaliza atualmente, com mais ênfase, que o mundo é outro e não há volta.

Um nível de consciência está se postulando, ao que nos sinaliza Katz, pensamos como os aplicativos, nossas vidas passaram a ser pautadas pela "lógica do aplicativo" (KATZ, 2015).

As coimplicações corpos/telas, enquanto sinais de mudanças já vinham ocorrendo. Nós que não prestamos muita atenção. Precisamos reconhecer que tal modo de operar foi elaborado por nós mesmos. Tudo que vamos criando nos modifica.

Nossas relações com o ambiente, efetivamente produzem algo em nós, que nos devolve a compreensão de que não somos máquinas, pois nosso cérebro e neurônios não concebem estruturas invariáveis com papeis fixos. Tudo que vivemos nos transforma.

Tudo o que vamos vivendo nos modifica. $\mathrm{E}$ a força do espiralamento permanente entre corpo e ambiente vai produzindo novas necessidades, que nos impulsionam a inventar o que é necessário para atendê-las. A percepção deste espiralamento é fundamental para que se compreenda que isso que a internet faz hoje conosco pertence à história evolutiva dos instrumentos que fomos inventando e que nos foram moldando. É também desta estreita relação de codependência entre corpo e ambiente que todas as mídias foram e continuam a ser descobertas/ inventadas/ produzidas/ exploradas. (KATZ, 2015, p.249)

Nos tempos de incessante conectividade como nos deparamos atualmente, o uso de cada uma delas tem a ver com o modo como existimos também. Esta existência espiralada se processa a partir do que recordamos e esquecemos, assim como no modo como resguardamos/encontramos o que efetuamos. Em outras palavras, criamos disponibilidades no corpo para toda essa ação cooperada que já existe em nós, elaborada por nós. Muitos nós.

A cada tecla digitada, acionamos jeitos de negociações com o mundo. A escrita de um papel com lápis de antes, virou também dígitos/telas, e agora mobilizam nossos dedos a deslizarem sobre dispositivos tecnológicos expondo nossos pensamentos de modos mais velozes e simultâneos. É assim, todos estamos plugados.

Dessa escrita apresento "coisas", uma referência a tudo que nos envolve em termos de possibilidades com esse mundo. Cabem pessoas, cidades, espaços, pensamentos, emoções, caminhos, ideias, plantas, 
florestas, bichos, gente, vontade, mar, pedra. Aqui também se evoca aqueles entes amados que partiram ou estão partindo. Enfim, tudo que nosso planeta concebe e nos compromete. Sabemos também que há outras coisas enquanto outros "Sóis", outros mundos. Nosso mundo, nossos mundos são processados dessas coisas vivas, cujos tempos, entre antes, depois e durante, permanecem em fruição constante.

Não é possível mais, pensar o mundo sem seus dispositivos tecs apartados de nós, pois, somos eles também. Evoco assim, Corpo sem vontade (BASTOS, 2017), uma ideia de corpo num continuum, o qual absorve também os aparatos tecnológicos enquanto extensões no modo como podemos/escolhemos agir. Um pensamento que busca se afastar dos imperativos de uma espécie de violência da positividade, que marcam a vida nas sociedades ocidentais contemporâneas.

Da escuta explorada nesse texto, aproximo a ideia de hospitabilidade compondo com alteridade e dessa forma expandir esses encontros enquanto estratégia política. Interesso-me pensar a dimensão poética da escuta como um posicionamento político. Tento entender a arte da poética que conhecemos desde tempos muito remotos, como uma estrutura política, distanciando-se de temas ou categorias. Para tanto, torna-se crucial nos perguntar: como este ou aquele mover faz falar o sujeito que ele mesmo produz? (BASTOS, 2017, p.80).

E por falar, precisamos escutar. Percebermos trânsitos a partir de fruições estéticas que a escuta pode nos acionar. Consequentemente, o entendimento de Corpo sem vontade aponta que se quisermos repensar os modelos de sujeito de desempenho é vital compreendermos variações dos nossos hábitos corporais, a fim de experimentarmos outros modos de engajamento corporal que emergem ao estabelecermos vínculos a partir dessa ideia de escuta que também se articula da codependência entre corpo ambiente.

Envolvo-me por espirais, desde o meu mestrado (1999). Talvez seja o modo como raciocino. Questiono nossa existência na tendência produtivista que vivemos ultimamente. Minha vontade é de uma provocação com outros 
em experiências estéticas na comunhão de outras travessias. Atravessar é um ato de reinvenção. Desse modo, muito sutilmente, proponho um sopro. Respiros breves entre fluxos de entradas e saídas. Expandir o espaço entre costelas e o diafragma. Inspirar, pausar e expirar. Penetrar, tatear e navegar. Evoco uma vela, simples, de parafina. Apesar de sua síntese ela é capaz de colaborar no modo como elejo caminhos. Ilumina aqui, contrasta ali. Leva tempo escutar silêncios. Precisamos de outro tempo para captar brechas em vazios. Tais vazios não tem luz, mas chama.

$$
* * *
$$

\section{REFERÊNCIAS}

BASTOS, Helena. Corpo sem vontade $=$ Cuerpo sin voluntad. Revisão e tradução: Martina Altalef. São Paulo: ECA/USP: Cooperativa Paulista de Dança, 2017.

DUNKER, Christian Ingo Lenz. Mal-estar, sofrimento e sintoma: uma psicopatologia do Brasil entre Muros. $1^{\text {a }}$ ed. São Paulo: Boitempo, 2015.

GLEIK, James. A informação. Uma história, uma teoria, uma enxurrada. Tradução de Augusto Calil. 1a.edi. São Paulo: Companhia das Letras, 2013. KATZ, Helena \& GREINER, Christine. Arte e Cognição. Organização Helena Katz; Christine Greiner. São Paulo, Annablume, 2015.

KRENAK, Ailton. O Amanhã não está à venda. São Paulo: Companhia das Letras, 2020.

LASHLEY, Conrad. Hospitalidade e hospitabilidade. Revista Hospitalidade. São Paulo, v. XII, n. especial, p. 70-92, mai. 2015.

MBEMBE, Achile. Necropolítica. Biopoder, soberania, estado de exceção, política da morte. N-1 edições, $3^{a}$ impressão, São Paulo, 2019. 
Políticas Da Inimizade. Tradução Marta Lança. Revisão

L. Baptiste Coelho. Portugal: Antígona, 2017.

SAGAN, Carl. Cosmos. Tradução de Angela Nascimento Machado; revisão técnica de Airtono. Lugarinho de Lima Câmara. Rio de Janeiro: Livraria Francisco Alves E S.A., 1981.

TEIXEIRA, Ana Cristina Echevenguá. A midiatização das Companhias Oficiais de Dança no Brasil: Ecos de Comunicação entre Público e Privado. Tese apresentada para obtenção de título de Doutor em Comunicação e Semiótica pela PUC/SP, 2012.

Recebido em agosto de 2020. Aprovado em setembro de 2020.

Publicado em outubro de 2020. 